\title{
Teaching Strategies Used to Develop Higher-Order Thinking Skills in Financial Accounting in Selected Schools in South Africa
}

\author{
Jabulisile Ngwenya ${ }^{*}$, Nombuso Q. Hlophe \\ School of Education, University of KwaZulu-Natal, South Africa \\ Received September 6, 2021; Revised November 12, 2021; Accepted December 13, 2021
}

\section{Cite This Paper in the following Citation Styles}

(a): [1] Jabulisile Ngwenya, Nombuso Q. Hlophe, "Teaching Strategies Used to Develop Higher-Order Thinking Skills in Financial Accounting in Selected Schools in South Africa," Universal Journal of Educational Research, Vol. 10, No. 2, pp. 173-183, 2022. DOI: 10.13189/ujer.2022.100206.

(b): Jabulisile Ngwenya, Nombuso Q. Hlophe (2022). Teaching Strategies Used to Develop Higher-Order Thinking Skills in Financial Accounting in Selected Schools in South Africa. Universal Journal of Educational Research, 10(2), 173-183. DOI: 10.13189/ujer.2022.100206.

Copyright $\bigcirc 2022$ by authors, all rights reserved. Authors agree that this article remains permanently open access under the terms of the Creative Commons Attribution License 4.0 International License

\begin{abstract}
Constant shifts in the accounting curriculum originate from the changes in the accounting discipline that occur due to the global developments in the accounting profession. These persistent curriculum changes emphasise the development of analytical skills that learners require in learning the subject. This paper explores teaching strategies used by accounting teachers to develop higher order thinking skills in Financial Accounting in Grade 11 in one district in South Africa. The study employed a qualitative case study to allow for an in-depth understanding of the strategies used to teach Grade 11 Financial Accounting. Teachers were conveniently and purposively sampled from four schools. Data generation methods were semi-structured individual interviews and lesson observations. The data were then analysed by identifying various themes that responded to the research question. Finding that emerged from the data is that teachers used scenarios and case studies that require learners to solve financial problems. However, teachers could not engage learners adequately in discussions and the analysis process due to insufficient teaching time and the length of the accounting curriculum. Teachers insisted on determining learners' understanding of foundational or prerequisite knowledge that was crucial in reinforcing learning of concepts needed in analysing financial problems. The findings of the study revealed that teachers understood that learners frequently struggled to solve unfamiliar financial problems due to the unique language
\end{abstract}

of the subject. As a result, they allowed learners to do complex calculations in groups and formulate diverse solutions together. Although teachers were eager to give learners more practice on problem-solving, insufficient activities in the textbooks and their condition hindered this practice.

Keywords Accounting, Curriculum Changes, Higher-Order Thinking Skills, Financial Accounting, Teaching Strategies

\section{Introduction}

Education systems globally emphasise the importance of teaching to help develop higher-order thinking skills to provide students with the skills they need to make logical decisions based on evaluative thinking $[1,2,3,4,5]$. The South African education system is not an exception in this regard. One of the central principles listed in the National Curriculum Statement (NCS) and in the Curriculum and Assessment Policy Statement (CAPS) document is to encourage a critical and active approach to learning while develop problem-solving and critical thinking skills $[6,7]$. An active and critical approach is associated with the main focus of accounting which is to analyse monetary data in order to solve financial problems $[6,8,9]$. 
The process of analysing, interpretation and reporting on the financial statements is viewed as the utmost purpose of the accounting process to enable future planning $[10,11]$. Therefore, the aim of accounting as a discipline is to instil in students the skills they need to think creatively and critically to solve accounting problems in order to make informed decisions $[6,11,5]$. This requires learners to engage with financial information to comprehend and analyse financial problems $[2,12,9]$.

Learners therefore need to be equipped with reasoning abilities as well as the ability to reflect on the financial accounting information by being exposed to familiar and unfamiliar situations $[13,14]$. This calls for teaching practice that should allow learners to develop analytical skills that are relevant to analyse and understand financial information and other appropriate data. Accounting teachers should not limit their teaching to formulas and figures only since the teaching of accounting necessitates the use of more scenarios and open-ended questions that allow learners to be engaged in discussions while being challenged to think critically $[15,11]$. Accounting teachers are, therefore, required to use conceptual and problem-solving teaching approaches to produce students who are acquainted with the thinking skills that are essential to succeed in further learning in Financial Accounting [5, 12].

In Accounting, there is increased complexity within each topic in the grade and across the grades. This complexity, which is evident in the hierarchical nature and sequencing of the topics, necessitates understanding and application of previously learnt knowledge in solving financial problems. Learners' ability to relay their previous knowledge to what is being taught develops higher-level thinking skills. Popil [4] further claims that to help learners to attain analytical skills, they must be able to relate new information to what is known in order to solve problems. This demands that accounting teachers use teaching strategies that would enable the learners to transfer knowledge and skills learnt in the classroom for application in real-life situations.

Although numerous studies have investigated teaching strategies used to enhance higher-order thinking skills [1, $2,3,16]$, there have been few studies conducted on teaching strategies that enhance higher-order thinking in accounting. Consequently, the main research question as follows was used to guide the study: What are the strategies used by accounting teachers to develop higher-order thinking skills to teach Financial Accounting in one district in South Africa?

\section{Literature Review}

This section reviews literature regarding conceptualising of higher-order thinking skills and why these skills are important in Accounting, and strategies used in teaching higher-order thinking skills.

\subsection{Conceptualising Higher-Order Thinking Skills (HOTS)}

According to Chinedu and Kamin [1], higher-order thinking skills (HOTS) are skills that entail evaluating and creating beyond the remembering and understanding of knowledge. According to the revised Bloom's Taxonomy, analysing, evaluating and creating are regarded as the higher-order category of the cognitive domain [17]. In the revised Bloom's Taxonomy, thinking is classified in terms of six hierarchical categories of cognitive complexity. The classification is progressive in nature, from lower-level to a higher level of thinking, with the highest level being create [17]. Since the complexity grows at each level of thinking, each succeeding category of cognitive domain incorporates all categories below it. Although the learning of the lower levels helps to build the skills that are essential in the higher levels of the taxonomy, HOTS involve level of reasoning that is higher than remembering facts and conveying them as they are. It involves a deeper understanding of facts, inferring from them, categorising them and connecting them to other facts and concepts. It entails adding something new and putting facts together in a new or different way. Therefore, higher-order thinking skills are related to creative thinking, reasoning, problem-solving, critical thinking and decision-making skills $[1,7,16]$.

HOTS are usually triggered when a person is faced with difficult problems or unfamiliar circumstances in the teaching and learning process. It is impossible to solve such problems through by simple application of prior knowledge since they require the individual to participate in creative and critical thinking and infer from previous knowledge [3]. During problem solving, HOTS involve evaluating information to ascertain the problem, analysing the problem, and suggesting practical results.

\subsection{The Importance of Higher-Order Thinking Skills in Accounting}

Accounting is one of the major subjects offered in the Further Education and Training (FET) phase (grades 10 to 12) in the South African secondary education. One of the key functions of accounting is to develop analytical skills in students so that they are able to assess and analyse various business scenarios and make informed decisions based on their evaluation $[18,5,19]$. Balakrishnan and Mohamed [20] explain that students who know how to analyse and critique ideas can make connections across the content within the disciplines. This helps them to see knowledge as valuable and applicable to real life. Encouraging learners to apply the knowledge assists in developing a deeper and more enduring understanding of 
content [19].

In order to enhance higher-order thinking skills, teachers are expected to involve students during the learning process and provide activities that promote thinking beyond comprehension. Such activities should promote analysis, synthesis, and evaluation. This will help learners to learn the deeper concepts from the learning materials rather than facts. Bhawani [18] elucidates that students with higher-order thinking skills become more independent and self-directed since they do not rely on teachers' instruction and guidance, and they are often more engaged in classroom activities and take ownership of their own learning.

\subsection{Strategies Used in Teaching Higher-Order Thinking Skills}

Teaching approaches used in teaching higher-order thinking skills include real-life scenarios, case-study analysis, role play, problem-based presentations, group discussions, individual and group projects and problem-solving.

\subsubsection{Problem-solving Based Learning}

Problem solving-based learning is also called problem-based learning (PBL). It involves presenting the problem to the students during the learning and teaching process, with the aim of encouraging them to develop critical thinking and analytical skills as they learn concepts instead of just absorbing facts. Supporters of this model suggest that problems presented to students must be based on real-life scenarios to encourage them to think critically $[21,22,4]$. Using scenarios allows teachers to ask open-ended questions that require learners to elucidate their thoughts in more detail when formulating responses. Because learners are asked to identify problems and provide solutions to the problems, they are encouraged to elaborate on their answers.

Because problem-solving requires the mastery of the previous knowledge, it is necessary for students to master basic concepts before proceeding to more sophisticated concepts $[22,23]$. This encourages students to use their prior knowledge in understanding problem-solving and making decisions [23]. In a study conducted by Brooks and Wilson [24], teachers used oral presentations based on problem solving to enhance students' communication and thinking skills in Accounting. Students were required to offer feedback to each other by clarifying their answers orally, and this encouraged them to consider diverse problem-solving methods [14].

\subsubsection{Cooperative Learning}

Cooperative learning is a teaching strategy that allows a small group of students to share thoughts, ideas, skills and experiences, aiming at working towards a common goal $[25,26,27]$. Moreover, it encourages students to be active participants in exploring what they are learning by asking questions and giving opinions rather than taking notes and memorising facts [26, 28]. Further, Kemp [25] believes that engaging students in small group activities can develop analytical skills and enhance individuals' understanding and ability to apply knowledge [27]. The active involvement of students also enhances the development of other skills, such as social skills, communication, listening, and thinking, which in turn help develop critical thinking skills $[19,16,27]$.

\subsubsection{Questioning}

Questioning is a tool that is frequently used by teachers both as an instructional strategy and as a means of assessment [29]. Research shows that the questioning technique is one of the most effective tools in developing critical thinking skills in students [29, 30]. Ellis and Shintani (2013) also state that the teacher must use open-ended questions to steer discussion and guide the teaching and learning process. These questions should be designed to allow students to take part in the group discussion process. Open-ended questions encourage students to elaborate on their answers by explaining their thoughts in more detail. This in turn helps develop critical thinking skills in students.

Etemadzadeh, Seifi and Far [30] conducted a study on the effectiveness of questioning techniques in enhancing critical thinking skills in learners. The study concluded that the questioning technique gives students the autonomy to ask questions without fear of being ridiculed or negative reactions from their peers or teachers. In the study conducted in Malaysia by Seime [31], teachers often used thought-provoking questions and elucidation of ideas in learners' activities in their classes. Teachers encouraged students to ask questions while others were expected to provide responses.

Zohar [19] found that although questioning promoted critical thinking, teachers tended to use more lower-order questions. Zohar [19] explains that the reason teachers rely heavily on lower-order questions may be due to a feeling of time pressure to keep pace with curriculum expectations, or pressure to prepare students for standardised tests.

\subsubsection{Simulation and Role Play}

Literature recommends simulation games as an effective strategy to enhance higher-order thinking skills in students [32, 33]. Several authors regard simulation games as one of the active learning strategies that help students to actively solve challenging situated problems.

In a study by Rojas and Villafuerte [34], teachers used role play as a method that gave learners an opportunity to apply content. This enhanced learners' communication and decision-making skills as they simulated various roles in varied topics. Daniau [32] argues that through the use of role play, learners were allowed to explore authentic 
situations by engaging with their peers in a managed manner to help nurture experiences, and this enhanced their critical skills.

\section{Theoretical Framework}

The theoretical background framing the study is constructivism, which is based on the view that knowledge is actively constructed by the learners based on previous knowledge and experience [35]. It encourages interaction, where teachers and learners work together to create new ideas by connecting to previous knowledge. Constructivism also holds that learners will apply previously learned knowledge and understandings to new or different situations [36]. This implies that teachers must create opportunities for learners to work with new material in such a way that it allows them to apply previously learnt concepts to make meaning of the new information taught. Bada and Olusegun [35] add that knowledge creation occurs in the processes of teaching and learning when the learners are actively involved and are learning with peers in class. Therefore, teachers should strive to encourage learners to share their point of view with one another.

Bada and Olusegun [35] proposed important elements that the constructivist teachers should consider when designing the learning content. Bada and Olusegun [35] explain that teachers should create spaces for learners to clarify their thoughts during the learning process. For example, in Accounting, learners may be asked to explain their solutions to financial problems. They should also organise groupings by compiling materials and grouping learners for interactive learning and an improved collaboration and information access. According to Yadav [37], a constructivist teacher should identify a yardstick for classifying learning materials according to their purpose, and design interactive tasks for cooperative and active learning. Because every individual learner is believed to have some previous experience related to what is learnt in the classroom, teachers should integrate learners' preceding experiences into the new learning environment [25].

Furthermore, teachers should prepare guiding questions that they will use to introduce new knowledge as well as encourage learners to ask questions during the lesson [36]. Moreover, teachers should encourage learners to jointly reflect on what they have learnt by giving them an opportunity to make presentations in groups. This will indicate the level of skills they have acquired and allow them to share their thinking with other learners.

Constructivism emphasises pedagogical practices, where learners are involved in critical thinking that produces ideas and innovative solutions to real-world problems [18]. The strategies that teachers should apply to enhance higher-order thinking skills are thus embedded in the constructivist theory [37].

\section{Methodology}

\subsection{Design}

This study is an interpretive qualitative case study positioned within the qualitative research method as the purpose was to gain a thorough understanding of teaching strategies [38]. Since we believe that multiple socially constructed meanings to a phenomenon are necessary, the researcher should observe and hear what the participants say they do [39]. The major assumption in a case study is that the phenomenon is explored as a bound system [40]. The bound system of this study was four Grade 11 accounting teachers.

\subsection{Sampling}

Participants were selected from four conveniently sampled secondary schools in one district in South Africa. The choice of one district was based on the schools' accessibility to us as researchers [39]. Purposive sampling was utilised to select four accounting teachers who were teaching accounting in Grade 11 in four schools where accounting was offered as a school major subject in the FET phase (grades 10 to 11). As a subject, accounting is offered in Grade 10 for the first time. Therefore, Grade 11 learners have already been exposed to the foundational knowledge that is required in developing higher-order thinking skills. These participants were selected on the basis that they were most likely to generate useful information [41], hence only a few participants should be involved in making sense and describing a phenomenon as it progresses in a natural situation. This supports the number of participants selected for this study.

\subsection{Data Generation}

The study adopted semi-structured individual interviews and lesson observations to generate data from the Grade 11 accounting teachers. Interviews took place during free time in the participants' workplace. The recording devise was used to record interviews that lasted 45 to 50 minutes each. The recorded interviews were transcribed verbatim to make sure that participants' responses were recorded correctly. Semi-structured observations were regarded to be an appropriate method of collecting data as we aimed at determining the teaching strategies utilised by teachers in enhancing higher-order thinking skills in Financial Accounting. Two lessons were observed to confirm the strategies teachers said they used in teaching Financial Accounting. They were conducted to get the required information to answer the research question. During lesson observations an observation 
schedule was used together with audio recording to capture what transpired in the lessons.

\subsection{Data Analysis}

Thematic analysis was used to analyse the data acquired from individual interviews and observations [37]. The data analysis process began by transcribing interviews and observations to word-based data. Thereafter, the transcripts were read several times to make sense of the responses received. Line by line analysis was utilised to identify categories which were revised and grouped into the specific themes that were used to report the findings.

\subsection{Ethical Considerations}

All ethical considerations were observed during the period of the study. The consent to conduct the research was acquired and granted by the university where the research took place. The participants were provided with all the relevant information regarding informed consent, voluntary participation, confidentiality and anonymity. The pseudonyms Camila, Avela, Delsie and Mavis are used to protect confidentiality and preserve the anonymity of the participants.

\subsection{A Profile of Grade 11 Accounting Teachers}

Camila is a deputy principal with 25 years teaching experience. She teaches Business Studies and Accounting in Grades 11 and 12. She was promoted to Deputy Principal after being a Head of the Commerce Department for numerous years. Her qualifications comprise a Secondary Teacher's Diploma, Bachelor of Commerce degree, as well as an Advanced Certificate in Education (ACE) in Accounting.

Avela is Head of the Commerce Department and has been teaching for 18 years. His qualifications include a Bachelor of Education and a Bachelor of Education Honours degree. He teaches Economics, EMS and Accounting in Grade 11.

Delsie has eight years of teaching experience as a post level 1 teacher. Her qualifications include a Bachelor of Commerce degree and a Postgraduate Certificate in Education (PGCE). She is currently studying towards a Bachelor of Education Honours degree. She teaches Economics and Accounting in Grade 11.

Mavis has been teaching for 16 years and has been a Head of the Commerce Department for six years. She has a Bachelor of Education and a Bachelor of Education Honours degree. She is registered for a Master's in Education degree. She teaches EMS and Accounting in grades 11 and 12 .

\section{Findings}

This section provides the findings that emerged in the form of themes that were developed from the generated data. The findings led to two themes: using real-life scenarios as a teaching strategy and supportive communal learning.

\subsection{Using Real-Life Scenarios as a Teaching Strategy}

Teachers acknowledged that more complex skills are critical to accounting owing to the type of the discipline of Accounting, which is centred on the analysis of financial problems. They mainly used real-life scenarios and case studies as teaching strategies to develop learners' analytical skills. However, teachers were concerned that it was often difficult for learners to analyse and solve real-life situations. They felt that leaners lack in-depth understanding of knowledge learnt in previous topics necessary to analyse financial problems. They believed that previous knowledge in accounting is essential since topics develop by building on each other within the grade and throughout the grades. As a result, there are topics that could not be taught without first teaching others because understanding of prior knowledge is central in evaluating financial problems.

Because accounting teachers regarded learners' previous knowledge as the crucial knowledge needed to solve financial problems, it was necessary to start lessons by accurately reviewing previous knowledge learners should possess before teaching the new content. Teachers used various strategies to ascertain what learners knew before introducing new topics. They clarified that they therefore began by assessing what learners previously knew before introducing new topic. Avela specified that he began the lesson by asking questions that emanate from previous knowledge associated to the new topic. Although preceding knowledge is critical to learning new concepts, learners often come to Grade 11 with insufficient basic knowledge. He felt that he was obliged to provide detailed explanations because his belief was that he could not proceed with teaching new content if learners lacked background knowledge. This is confirmed below:

"I ask them questions on previous knowledge with the purpose of checking what they know and taking them from known to unknown. When I find that they don't know most of the information, I know that I have to start by explaining it to them because they need this information when they are given ethics questions." (Avela)

Avela specified that it was crucial to begin his lessons with what the learners knew and continue to the unknown by linking what learners knew about the new concepts. 
When asked about the process they followed when using scenarios involving unfamiliar problem-solving as a strategy, teachers explained that the starting point was to recognise the problem by evaluating the given scenario. They further clarified that learners were expected to offer solutions and defend their opinions by quoting figures.

An emphasis on understanding the scenarios involved in identifying the problem was noticeable in Camila's lesson. The lesson was about Control of Working Capital and learners were required to solve the problem on stock turnover.

Camila: The following information has been extracted from the financial statement of Zakhe LTD. Provided are the figures and financial indicators from the journal for 2019 and 2020. Let's read the question.

Learners: Give your opinion on the control of stock of Zakhe LTD. Justify your comments by quoting figures or financial indicators. Why do you think Zakhe LTD should be worried about the stock? Provide advice on how Zakhe would do to control stock. Provide two points.

Camila: What do we do first?

Learners: We need to read all the information related to the stock.

Camila: What else do we have to do?

Learner: We also need to look at the financial indicators and stock to find how they are controlling the stock.

Camila: Right, what is the problem with stock?

Learner: The stock is missing.

Camila: What else?

Learner: The stock turnover rate is affected by the missing stock.

Camila: Now do the calculations to see how much is missing.

Camila: What can you say about your answer, look at your answer and compare with ratios.

Learner: Stock has decreased and stock turnover rate has also decreased.

Camila: What effect does that have on the holding period?

Camila followed a process that confirmed the knowledge of what might enhance or hamper learners' development in making sense of problem-solving. Camila also offered successive support to assist learners in making sense of the instructions and comprehend the information provided. This kind of support helped learners recognise information to evaluate in recognising the problem. The knowledge and understanding of financial indicators were vital in commenting on stock turnover and providing advice.

Although Camila was able to involve learners in solving the problem, the teachers were concerned about the time learners take in evaluating scenarios due to the length of the Grade 11 curriculum. They stated that there was too much content to cover in the accounting curriculum, and the time allocated did not accommodate active teaching strategies, such as the problem-based method, that require learner involvement. As a result, time allocated to accounting per week did not allow space for teachers to fully engage learners in problem-solving activities in class. This is what Delsie said:

"Our periods have a fixed time and the accounting syllabus is long. It is difficult to use other methods like involving learners. When we teach problem-solving, learners need more time to read and understand the cases and scenarios. They take time to discuss the scenario and come up with answers. The truth is that using strategies that involve learners is very time consuming. We end up giving them answers to the problems." (Delsie)

What teachers said was evident in Mavis's lesson. Although learners were given the opportunity to read the case study, she denied them the opportunity to thoroughly discuss the issues raised in the case study. She asked the learners few questions and no time was allowed for further discussion to offer diverse opinions with substantive solutions.

Teachers were concerned that learners often encountered challenges in framing answers to the financial problems. They specified that even if learners had identified problems in given scenarios, they found it difficult to put responses together. Teachers were of the opinion that training should be offered to learners to apply their understanding of financial knowledge required to solve any financial problem. To consolidate knowledge of problem-solving, teachers generally gave learners more activities to make sure they were regularly exposed to questions that necessitate them to solve financial problems. While teachers used problem-solving activities from the prescribed textbooks, the cases were elementary and did not require learners to thoroughly engage with financial information. Teachers also indicated that some cases were not related to the learners' present experiences because they were old. This was due to the fact that accounting textbooks were outdated. This was concerning because the accounting profession is dynamic and ever-changing, and updated material should be used during classroom instruction. Teachers ended up relying heavily on problem-solving questions from past examination papers. This is confirmed by Delsie:

"I take cases from previous exam papers related to the topic and ask them to assume a particular role 
and to draw on their own experience or on prior learning to interpret, analyse and solve problems. There are not enough problem-solving questions in the textbooks. Books are old and they have old case studies and they are not real." (Delsie)

Delsie believed in giving learners authentic financial problems to increase their analytical skills. However, she was concerned that textbooks did not have authentic scenarios and they were outdated.

\subsection{Supportive Communal Learning}

Teachers acknowledged the necessity of actively involving learners in the learning and teaching process in Accounting. Therefore, they allowed spaces for learners to do their work together by providing them with activities to discuss in class. This provided opportunities for making sense of the new content and helped to expand understanding. Moreover, they motivate learners to actively participate in exploring what they were learning by asking questions. They mentioned that when teaching in class, they allowed learners to give opinions rather than taking notes and memorising new content. Teachers thought that involving learners in small group activities could help develop analytical skills, thereby enhancing individual understanding and the ability to apply knowledge.

Teachers indicated that they motivate learners to engage in group discussion so they could help each other. After group discussions, they often created opportunities for learners to share their solutions in class. During presentations, learners were required to explain their solutions by doing calculations on the board while other groups asked questions. The motive was to engage the entire class in interrogating or to support the presentation. This is confirmed by Mavis:

\section{"I group them in five. I give them activities to discuss as a group and give each learner two minutes to present in the classroom and allow other groups to ask questions for clarity, and also allow their peers to add more information."}

Teachers were anxious that the distinctive language of the accounting discipline posed serious difficulties in learning concepts that are pertinent in understanding financial information. While the language of teaching frequently hampered the effective learning of Accounting, teachers believed that challenges are exacerbated by the language of the subject. Teachers explained that the language of accounting is not familiar, and vocabulary used in the subject is problematic to adept. As a result, learners who were not confident in the language of teaching often encountered challenges in understanding the unique concepts. Because learners failed to understand background concepts, they frequently struggled to offer reasonable explanations to the financial problems. They found it thought-provoking to formulate answers due to inadequate understanding of financial information and language limitations in communicating in the language of teaching, which is English.

Teachers stated that because learners often grapple with the analysis of financial information, they normally used group discussions and presentations to improve development in communication and decision-making skills. Teachers were of the opinion that active involvement of learners in group work helped in the development of other essential skills required to understand and report financial information in Accounting. As a result, teachers use open-ended questions to stimulate discussions and to guide the learning process. This encouraged learner involvement during the group discussion process. Open-ended questions gave learners an opportunity to formulate diverse solutions as they were actively involved during the discussion process. Learners were free to offer their responses and were encouraged to explain and elaborate on their thoughts. Camila felt that learners liked interacting in groups because they could express themselves in a relaxed manner. This enhanced collaborative and social skills that allowed them to engage and make decisions regarding the utmost accurate solutions. This is what she said:

"I encourage them to do problem-solving exercises in groups. I want them to present their answers to increase accounting communication skills. Therefore, for learners to acquire communication and decision-making skills, they do work together and converse well with others, they communicate freely with their peers. They discuss or share ideas and present them in the class, where other groups ask questions for clarity."

Camila acknowledged the benefits of creating spaces for group work. She pointed out that her learners knew that they had to do problem-solving activities together, led by group leaders. Although there was insufficient time to engage learners in discussion, she was of the opinion that allowing learners to work and discuss in groups necessitated learners to spontaneous exchange of information among learners, and this enhanced their communication and thinking skills.

Teachers added that they inspired learners to do complex calculations in groups to give them a chance to deliberate their solutions together. They believed that if they gave learners an opportunity to offer answers, they would be more likely to formulate their particular strategies for solving financial problems. During group discussions, learners formulated different methods of calculating difficult calculations and this helped other learners to get diversity of solutions. Avela explained that he often gave learners chance to work out answers and to provide justification for their solutions because different learners think differently. 
"When I teach, I always give them time to think and tell us what they know. I want them to all participate by giving their different answers. They have something to say. They have to talk in class." (Avela)

Teachers viewed accounting as a subject that needed learners to work in groups to share various methods of performing complex procedures. Learners formulated different methods of calculating difficult calculations.

Delsie shared sentiments similar to the other two teachers by suggesting that the enhancement of critical skills could be improved by affording opportunities for cooperative work where learners are provided with scenarios and are expected to offer solutions to authentic problems. What Delsie mentioned is demonstrated in her lesson below, where she promoted group discussions by asking learners to formulate the solutions in groups. They were later asked to prepare group presentations:

Delsie: Let's read the question. On 31 July, Zungu increased deposited R150 000 into the bank account of the business to increase his capital, On 1 August, Muzi reduced her capital because she wanted her capital to be equal that of Bantu.

Delsie: Give reasons that lead to decision made by the partners to equalize their capital.

Delsie: Respond to this question in groups and prepare for presentation. Each group is going to give one reason.

Teachers believed that learners' understanding is enhanced if they discussed the work in groups with their peers. In the above lesson, learners started by brainstorming and sharing ideas in a discussion. After working out solutions together, they presented their solutions in class.

\section{Discussion of Findings}

This study sought to explore teaching strategies used by Grade 11 teachers to develop higher-order thinking skills in Financial Accounting. Based on the fundamental focus of accounting that is the analysis of financial information, it is revealed that teachers mainly used scenarios and case studies as a teaching strategy to instil analytical skills in learners. When provided case studies and scenarios, the learners are expected to employ their accounting knowledge to evaluate and solve financial problems and offer valid solutions [20, 21, 8]. However, teachers raised concerns that learners frequently encounter difficulties in solving unfamiliar financial problems due to lack of in-depth understanding of real-life scenarios which require application of knowledge learnt in previous topics [23]. According to Bada and Olusegun [35], constructivism is based on the notion that the learners apply their previous knowledge and experience as a basis for actively constructing new knowledge.

In line with the constructivism view, teachers created learning spaces for learners to comprehend accounting new knowledge by establishing links between prior understanding and new accounting knowledge [37]. Consequently, they apply diverse strategies to ascertain learners' previous knowledge and experience from preceding grades and determine how a specific concept is related into learners' future studies in accounting [23]. The main aim was to ensure that learners would be able to apply previously learnt knowledge and understandings to new or different situations [36].

According to Alsalman [15], using the scenario or case study method helps to nurture learners' critical thinking and analysis skills as they discuss and solve real-life problems together. Constructivism stresses pedagogical practices where learners are involved in critical thinking, which brings out innovative solutions to real-world problems [37]. However, teachers were concerned that they could hardly allow extended discussions because they had insufficient time to complete the lessons as per the teaching plan. Although teachers understood the value of involving learners in analysing and discussing the scenarios, they were constrained to a large extent by time and the length of the accounting curriculum.

In Accounting, learning happens generally through the constant practice of diverse skills owing to the practicality of the subject $[8,12,10]$. In this study, teachers recognised the essential use of practice to consolidate knowledge of problem-solving and to expose learners to questions that require the use of analytical skills. However, findings showed that teachers were worried that students were oftentimes exposed to less challenging familiar problems because textbooks had very few open-ended unfamiliar questions that entail students to use profound processing critical thinking skills. Furthermore, scenarios were not based on current real-life experiences due to the fact that accounting textbooks are outdated. This finding is inconsistent with Dawson and Titz [22], who emphasise that linking new information to students' experiences helps them to comprehend the new concepts better. In this study, it is concerning because the accounting profession is ever-changing and teachers are required to stay abreast of current developments and practices. The implication is that case studies must be recent and reflect current trends in the accounting industry $[15,21]$. As case studies were taken from old textbooks, this might suggest that the learners were not exposed to the latest developments in the accounting discipline.

Teachers thought it was imperative to involve learners throughout the learning and teaching process in Accounting. Consequently, teachers created spaces for learners to do their work collaboratively by assigning them group activities to deliberate in class. In line with the constructivist approach, teachers were expected to allow learners to actively learn together in class by encouraging 
them to do activities in groups while sharing information with peers [36, 27]. Teachers emphasised the use of diverse approaches in manipulating the figures for learners to develop competence and accurateness in mathematical calculations so that they could master procedural skills. Hence, they allowed the learners to share their opinion through partaking in formulating answers for complex calculations in groups. This finding is confirmed in Ngwenya's [14] study, where it was found that learner-to-learner collaboration was viewed as a significant approach for effective teaching of Accounting. It enhances communication and social skills as learners are granted an opportunity to talk freely without fear of being ridiculed.

Myers [10] regards accounting as a subject that necessitates teachers and learners to possess a shared understanding of the peculiar concepts found in the field. Myers [10] found that when students encountered with new concepts, they had to begin by translating accounting concepts into the language of teaching and then interpret them into unique connotations in the accounting discipline. This is consistent with the findings of this study, where teachers were worried that the special language of the accounting discipline, combined with the medium of instruction, hindered effective learning since learners often struggled to interpret financial problem questions owing to language obstacles.

\section{Conclusion and Recommendations}

Stemming from the persistent need to instil relevant knowledge and skills learners required to analyse and make sense of financial information, this article sought to explore teaching strategies used in Grade 11 accounting to support development of higher-order thinking skills in Financial Accounting. The findings of this paper indicated that teachers normally used scenarios and case studies as teaching strategies to give learners an opportunity to develop the accounting knowledge skills required in solving financial problems. Teachers were of the opinion that the active involvement of learners in group discussion helped in the development of the vital skills essential to understand and communicate financial information in Accounting. This supported learners to observe things from several viewpoints, use reasoning to defend their opinions, and advance their communication and critical thinking skills, particularly when challenged with scenarios that involve various solutions. While teachers created spaces for learners to take on a proactive direction to learning in order to develop communal knowledge, the length of the curriculum hindered teachers from giving learners enough time to engage in discussions.

Teachers knew that all learners brought their own prior experience of abstract understanding, skills and beliefs into an accounting classroom as they carried their previous knowledge and individual experiences from preceding grades. Hence, they introduced their lessons by building the bridge between what learners know with new knowledge.

Findings revealed that teachers used practice activities on evaluation of scenarios as a strategy to consolidate critical thinking skills. However, prescribed texts could not allow learners to engage in thorough practice because of a shortage of activities on authentic financial problems and the fact that textbooks were outdated.

The recurring changes in the accounting curriculum due to changes in the accounting industry entails that accounting teachers should be offered consistent staff development and training to be updated of new changes in the accounting profession. This would equip them with pertinent strategies in line with the constantly changing curriculum. Furthermore, meanwhile teachers appear to rely profoundly on textbooks and regard them as main teaching resources. These should be revised regularly. More recent materials should be provided for update teachers of the changes to supplement the outdated sections in the textbooks.

The study is limited in that it only represents the strategies of four teachers from one district. Although accounting is taught from grades 10 to 12 , the study focused on Grade 11 accounting teachers. The results can therefore not be generalised outside this sample. Likewise, possible further studies can expand on the wider scope of strategies used in enhancing critical thinking skills in Financial Accounting, which could produce varied results. Furthermore, action research could be conducted to analyse the obstacles, and possible solutions in moving towards different methods of teaching accounting, including case studies and scenario analysis with the aim of enhancing higher-order thinking skills.

\section{REFERENCES}

[1] Chinedu, C., \& Kamin, Y., Strategies for Improving Higher Order Thinking Skills in Teaching and Learning of Design and Technology Education. Journal of Technical Education and Training (JTET), Vol. 7, No.2, 35-43, 2015.

[2] Naser, I. The Effect of Using Brainstorming Strategy in Developing Creative Problem-Solving Skills among male Students in Kuwait: A Field Study on Saud Al-Kharji School in Kuwait City, 2015.

[3] Noraini, O., \& Khairul, A. M., Thinking Skill Education and Transformational Progress in Malaysia. International Education Studies, Vol. 7, No. 4, 27-32, 2014.

[4] Popil, I. Promotion of critical thinking by using case studies as teaching method. Nurse Education Today, Vol. 31, No. 2, 204-207, 2011.

[5] Thompson, F. \& Washington, H.L. Critical thinking skills and teaching Accounting: A comparative study. Journal of 
Finance and Accountancy, Vol. 19, No. 1, 1-8, 2015.

[6] Department of Basic Education. Curriculum and Assessment Policy Statement. Grades 10-12. Accounting. Pretoria: Government Printers. 2011.

[7] Nwosu, L., Bechuke, A., \& Moorosi, P. Towards an Effective Management on the Teaching and Learning of Accounting in Secondary Schools: Case Report. British Journal Research, Vol. 5, No. 1, 1-8, 2018

[8] Erasmus, L. J., \& Fourie, H. Inclusive accountancy programmes in South African higher education: A revised teaching approach. Accounting Education, Vol. 27, No. 5, 495-512, 2018.

[9] Umalusi. What's in the CAPS Package? A Comparative study of the National Curriculum Statement (NCS) and the Curriculum and Assessment Policy Statement (CAPS): FET Phase Accounting, South Africa, Pretoria, 2014.

[10] Myers, L. P. Knowledge structures and their relevance for teaching and learning in introductory financial accounting. South African Journal of Accounting Research, Vol. 30, No. 1, 79-95, 2016.

[11] Omotayo, B. K. Teachers' characteristics and students' performance level in senior secondary school Financial Accounting. Journal of Empirical Studies, Vol. 1, No. 2, 48-53, 2014.

[12] Alao, O. E., \& Ukpong, M. J. Instructional Resources and Effective Pedagogy of Financial Accounting in Secondary Schools, Lagos, Nigeria. International Business Education Journal, Vol. 13, 94- 108, 2020.

[13] Abbott, J.I., \& Palatnik, B.R. Students' perceptions of their accounting class: Implications for instructors. Accounting Education, Vol. 27, No. 1, 72-93, 2018.

[14] Ngwenya, J. Accounting teachers' experiences of communal feedback in rural South Africa. South African Journal of Education, Vol. 39, Supplement No. 2, S1-S10, 2019.

[15] Alsalman, A.M. The effectiveness of using [the] case-based learning approach: Student perceptions and assessment tools used in [an] Accounting case study course. Australian Journal of Basic and Applied Sciences, Vol. 11, No. 10, 26-40, 2017.

[16] Okwelle, P. C., \& Owo O. T. Effects of collaborative learning on academic performance of student in technical drawing in Rivers State University Port Harcourt, Nigeria. International Journal of Education Benchmark, Vol. 9, No. 1, 70-79, 2018.

[17] Anderson, L. W \&, Krathwohl, D. R. A taxonomy for learning, teaching, and assessing: A Revision of Bloom's Taxonomy of Educational Objectives. New York: Longman, 2001

[18] Bhawani, P. M. Higher Order Thinking in Education. Academic Voices, A Multidisciplinary Journal. Vol. 2 No. 1, $5-9,2012$.

[19] Zohar, A. Challenges in wide scale implementation efforts to foster higher order thinking (HOT) in science education across a whole wide system. Thinking Skills and Creativity, Vol. 10, 233-249, 2013.
[20] Balakrishnan, K., \& Mohamed, M. Teachers' Teaching Methods in Teaching Higher Order Thinking Skill (Hots) Comprehension Questions. International Journal of Academic Research in Business and Social Sciences, Vol. 10, No. 2, 362-378, 2020

[21] Bonney, K.M. Case study teaching method improves student performance and perceptions of learning gains. Journal of Microbiol Biol Educ, Vol. 16, 21-28, 2015.

[22] Dawson, M. \& Titz, K. Problem-based learning as a strategy to teach service quality: An assessment of on-line reviews. Journal of Hospitality \& Tourism Education, Vol. 24, No. 2-3, 67-72, 2012.

[23] Hattan, C. Prompting rural students' use of background knowledge and experience to support comprehension of unfamiliar content. Reading Research Quarterly, Vol. 54, No. 4, 24-47, 2019.

[24] Brooks, G., \& Wilson, J. Using Oral Presentations to Improve Students' English Language Skills. Kwansei Gakuin University humanities review, Vol. 19, 199-212, 2015.

[25] Kemp, S. J. Exploring the use of learner-focused teaching approaches in different academic disciplines. Journal of Further and Higher Education, Vol. 37, No. 6, 804-818, 2013.

[26] Gull, F., \& Shehzah, S. Effects of cooperative learning on students' academic achievement. Journal of Educational \& Learning, Vol. 9, No. 3, 246-255, 2015.

[27] Virgana, F. Understanding of mathematical concepts through cooperative learning and learning style. Journal of Education \& Learning, Vol. 13, No. 2, 212-218, 2019.

[28] Siti, N. B. M. Teachers' perception on the integration of HOTS in language teaching. International Journal of Technical Research and Applications, Vol. 15, 561-575, 2016.

[29] Smith, V., \& Szymanski, A. Critical thinking: more than test scores. NCPEA International Journal of Educational Leadership Preparation, Vol. 8, 16-26, 2013.

[30] Etemadzadeh, A., Seifi, A., and Far, H. R. The role of questioning in developing thinking skills: the going effect on writing skills. Procedia- Social and Behavioural Science, Vol. 70, 1024-1031, 2013.

[31] Seime, K. An exploration of the relationship among the type of teachers' questions, student proficiency and wait time. Ethiopian Journal of Education, Vol. 22, No. 2, 32-19, 2015.

[32] Daniau, S. The Transformative Potential of Role-Playing Games-: From Play Skills to Human Skills. Simulation \& Gaming, Vol. 47, No. 4, 423-444, 2016.

[33] Stevens, R. Role-play and Student Engagement: Reflections from the Classroom. Teaching in Higher Education, Vol. 20, No. 5, 481-492, 2015.

[34] Rojas, M.A., \& Villafuerte, J. The Influence of Implementing Role-play as an Educational Technique on EFL Speaking Development. Theory and Practice in Language Studies, Vol. 8, No. 7, 726-732, 2018. 
[35] Bada, S.O. \& Olusegun, S. Constructivism learning theory: A paradigm for teaching and learning. Journal of Research \& Method in Education, Vol. 5, No. 6, 66-70, 2015.

[36] Kalpana, T. A constructivist perspective on teaching and learning: A conceptual framework. International Research Journal of Social Sciences, Vol. 3, No. 1, 27-29, 2014.

[37] Yadav, R. Role of constructivism in learning. International Journal of Educational Studies, Vol. 3, No. 3, 93-97, 2016.

[38] Cohen, L., Manion, L., \& Morrison, K. Research methods in Education (8th ed). New York: Routledge, 2018.

[39] Creswell, J.W. \& Poth, C.N. Qualitative inquiry and research design: Choosing among five approaches (4th ed.). Thousand Oaks, CA: SAGE, 2018.

[40] Yin, R.K. Case Study Research Design and Methods (6th Ed.). Thousand Oaks, CA: Sage Publishing, 2018.

[41] Farrugia, B. Write a science paper: sampling in qualitative research. Early Human Development, Vol. 133, 69-71, 2019. 